\title{
Perencanaan Pondasi Jembatan dan Perbaikan Tanah untuk Oprit Jembatan Overpass Mungkung di Jalan Tol Solo-Ngawi-Kertosono STA $150+331$
}

\author{
Prathisto Panuntun Unggul Listyono, Suwarno, dan Putu Tantri Kumala Sari. \\ Jurusan Teknik Sipil, Fakultas Teknik Sipil dan Perencanaan, Institut Teknologi Sepuluh Nopember (ITS) \\ J1. Arief Rahman Hakim, Surabaya 60111 Indonesia \\ e-mail: soewarno@ce.its.ac.id, tantrigeoteknik@gmail.com
}

\begin{abstract}
Abstrak - Mainroad jalan Tol Solo-Ngawi-Kertosono pada STA $150+331$ terdapat perencanaan jembatan overpass Mungkung. Oprit jembatan overpass Mungkung berdiri di atas tanah dasar lempung lunak, sehingga tanah dasar memiliki daya dukung yang rendah yang dapat mengakibatkan kelongsoran pada oprit timbunan dan memiliki kemampumampatan yang tinggi. Pada Penelitian ini struktur bawah jembatan overpass Mungkung direncanakan memiliki 3 buah pilar dan 2 buah abutment. Untuk oprit timbunan jembatan akan direncanakan metode perbaikan tanah dasar menggunakan preloading yang dikombinasikan dengan Prefabricated Vertical Drain (PVD) dan Prefabricated Horizontal Drain (PHD). Untuk perkuatan oprit akan direncanakan 2 alternatif perkuatan yaitu dengan geotextile wall atau sistem freyssisol. Pada tahap akhir dilakukan analisis perbandingan dari 2 alternatif untuk sistem perkuatan oprit jembatan.

Dari hasil analisis didapatkan untuk alternatif 1 yaitu dengan geotextile walls diperoleh kebutuhan geotextile untuk $H$ oprit 3 m - 8 m adalah 5 - 27 lapis. Pada perkuatan memanjang diperoleh kebutuhan geotextile sebanyak 27 lapis. Pada alternatif 2 yaitu dengan freyssisol diperoleh masing-masing kebutuhan paraweb straps untuk Tu $30 \mathrm{kN}$ adalah $183,2 \mathrm{~kg}$, untuk Tu $50 \mathrm{kN}$ adalah $967,9 \mathrm{~kg}$, dan untuk Tu $100 \mathrm{kN}$ adalah $2587,1 \mathrm{~kg}$. Untuk perkuatan memanjang diperoleh kebutuhan geotextile sebanyak 11 lapis.

Dari kedua alternatif dipilih alternatif 1 karena ketersediaan material geotextile di Indonesia dan kemudahan mendapatkan material dibanding freyssisol yang harus diimpor dari luar Indonesia. Pondasi pilar 1 (pilar tengah) adalah tiang pancang dengan diameter $60 \mathrm{~cm}$ sebanyak 25 buah dan kedalaman tiang 27,5 m. Pondasi pilar 2 adalah tiang pancang dengan diameter $60 \mathrm{~cm}$ sebanyak 16 buah dan kedalaman tiang 27,5 m.Pondasi abutment adalah tiang pancang dengan diameter $60 \mathrm{~cm}$ sebanyak 24 buah dan kedalaman tiang 27,5 m.
\end{abstract}

Kata kunci - Abutment, Geotextile Wall, Freyssisol, Pilar, Jembatan Overpass Mungkung, Prefabricated Horizontal Drain, Prefabricated Vertical Drain.

\section{PENDAHULUAN}

\section{A. Latar Belakang}

Ј $\mathrm{A}$ ALAN Tol Solo-Ngawi-Kertosono memiliki panjang jalan 177,02 km. Di mana ruas Jalan Tol Solo-Ngawi adalah sepanjang $90 \mathrm{~km}$ dan ruas Jalan Tol Ngawi-Kertosono adalah sepanjang 87,02 km. Pada STA 150+331 terdapat perencanaan mainroad yang melewati perpotongan jalan antar Desa Mungkung, sehingga diperlukan perencanaan jembatan overpass.

Jembatan overpass Mungkung direncanakan memiliki 2 buah abutment dan 3 pilar dengan bentang total $86 \mathrm{~m}$. Pilar dan abutment jembatan direncanakan memiliki struktur yang kuat dalam memikul beban vertikal dan horizontal serta tahan terhadap gaya gempa pada zona gempa 4. Di bagian belakang masing-masing abutment akan direncanakan oprit jembatan. Oprit jembatan harus dibuat sepadat mungkin agar perkerasan jalan diatasnya dan struktur sambungan abutmennya tidak mengalami kerusakan. Sehingga penurunan (settlement) dapat dihindarkan agar tidak membahayakan bagi kendaraan yang melewati atau berhenti di jembatan overpass Mungkung.

Lokasi perencanaan dan potongan memanjang jembatan overpass Mungkung dapat dilihat pada Gambar 1 dan Gambar 2. Rencana oprit jembatan dengan tanah timbunan paling tinggi adalah sebesar $8 \mathrm{~m}$. Tanah dasar timbunan pada oprit jembatan memiliki nilai NSPT rata-rata $=8$ yaitu termasuk medium clay sampai dengan kedalaman $16 \mathrm{~m}$ yaitu tanah dasar lunak yang lembek yang daya dukungnya rendah dan kemampumampatannya tinggi. Daya dukung tanah yang rendah akan menyebabkan terjadinya kelongsoran pada oprit jembatan yang menimbulkan bahaya pada konstruksi jembatan di sebelah oprit jembatan. Selain itu, kemampumampatan yang tinggi menyebabkan terjadinya perbedaan penurunan konsolidasi. Dibutuhkan alternatif metode perbaikan dan perkuatan tanah dasar timbunan agar mampu menahan beban sehingga kelongsoran dan perbedaan penurunan konsolidasi tidak terjadi.

Pada Penelitian ini akan direncanakan perbaikan tanah dasar untuk perencanaan oprit timbunan yaitu preloading yang dikombinasikan dengan Prefabricated Vertical Drain (PVD) dan Prefabricated Horizontal Drain (PHD). Untuk perkuatan oprit akan direncanakan 2 alternatif perkuatan yaitu alternatif pertama dengan geotextile wall sebagai perkuatan timbunan dan alternatif kedua yaitu dengan sistem tembok freyssisol. Dari 2 alternatif untuk metode perbaikan tanah dan 2 alternatif untuk perkuatan oprit timbunan tersebut akan dipilih masing-masing salah satu alternatif yang paling efisien dan efektif untuk dilaksanakan. Untuk struktur atas jembatan akan direncanakan dari PCI girder yaitu dari beton precast dan terdapat 3 buah pilar dan 2 buah abutment.

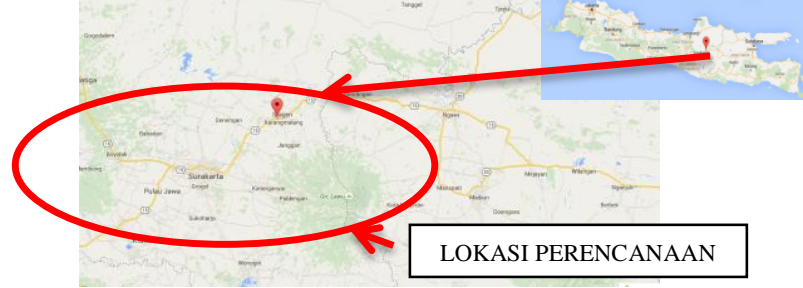

Gambar 1. Lokasi Perencanaan Proyek Jalan Tol Solo-Ngawi-Kertosono 


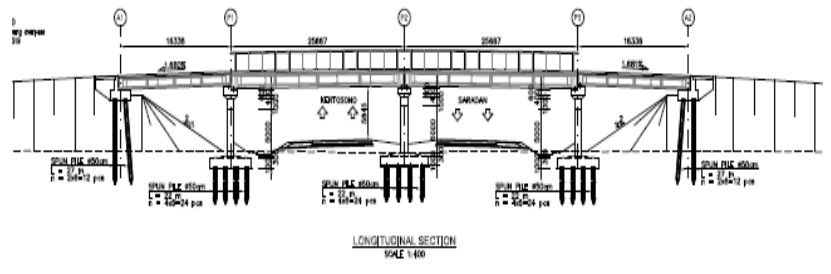

Gambar 2. Potongan Memanjang Perencanaan Jembatan overpass Mungkung

\section{B. Rumusan Masalah}

Dari uraian diatas, beberapa permasalahan yang akan dibahas dalam Penelitian ini adalah sebagai berikut:

1. Bagaimana hasil perencanaan pondasi jembatan untuk pilar dan abutment?

2. Bagaimana hasil perencanaan perbaikan tanah dasar menggunakan preloading yang dikombinasikan dengan Prefabricated Vertical Drain (PVD) dan Prefabricated Horizontal Drain (PHD), apabila dari hasil analisis data tanah memerlukan metode tersebut?

3. Bagaimana hasil perencanaan perkuatan oprit timbunan dengan menggunakan geotextile wall?

4. Bagaimana hasil perencanaan perkuatan oprit timbunan dengan menggunakan sistem tembok freyssisol?

5. Alternatif perkuatan oprit timbunan mana yang lebih tepat diterapkan untuk oprit jembatan overpass Mungkung di jalan Tol Solo-Ngawi-Kertosono STA 150+331?

\section{Batasan Masalah}

Adapun batasan masalah dalam penyusunan Penelitian ini adalah sebagai berikut:

1. Data yang digunakan adalah data sekunder yang berasal dari kontraktor Jalan Tol Solo-Ngawi-Kertosono.

2. Tidak membahas perhitungan geometri dan perkerasan jalan.

3. Tidak merencanakan drainase jalan.

4. Biaya yang diperhitungkan adalah biaya material.

\section{Tujuan Penelitian}

Adapun tujuan yang ingin dicapai dalam Penelitian ini adalah merencanakan pondasi jembatan, perbaikan tanah dasar untuk oprit timbunan, dan perkuatan oprit timbunan agar mampu menerima beban sehingga tidak terjadi kelongsoran dan perbedaan penurunan pada oprit jembatan overpass Mungkung yang dapat menyebabkan kerusakan pada perkerasan jalan di atasnya dan struktur sambungan abutmentnya.

\section{E. Manfaat Penelitian}

Perencanan dalam Penelitian ini adalah dimaksudkan agar dapat menjadi alternatif pondasi jembatan, perbaikan tanah dasar untuk oprit timbunan, dan perkuatan oprit timbunan pada oprit jembatan overpass Mungkung pada Jalan Tol Solo-Ngawi-Kertosono STA $150+331$ yang mungkin bisa dijadikan bahan pertimbangan oleh para pengambil keputusan di Proyek Jalan Tol Solo-NgawiKertosono.

\section{METODOLOGI}
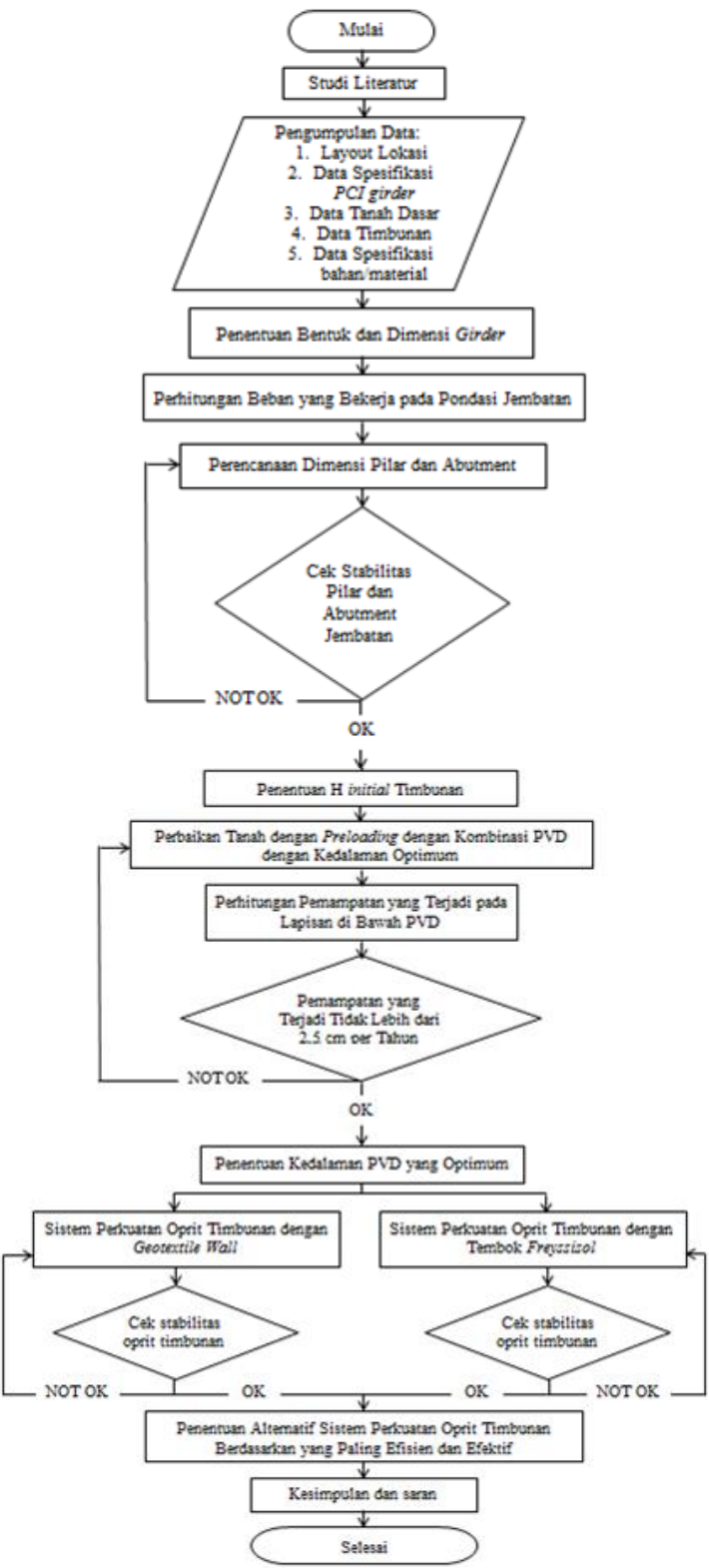

Gambar 3. Diagram Alir Penelitian

\section{HASIL DAN PEMBAHASAN}

\section{A. Analisis Data Perencanaan}

\section{Data Tanah}

Data tanah dasar yang diketahui dari hasil laboratorium untuk borlog 1 (BH-1) dan borlog 2 (BH-2) adalah nilai Gs, e, Sr, Wc, n, Yt, Yd, Ysat, LL, PL, IP, dan $\mathrm{C}_{\mathrm{u}}$. Hasil rekap data tanah dasar BH-1 dan BH-2 dapat dilihat pada Tabel 1 dan Tabel 2.

Tabel 1.

Hasil Rekap Data Tanah Dasar BH-1

\begin{tabular}{|c|c|c|c|c|c|c|c|c|c|c|c|}
\hline $\begin{array}{c}\text { Kedalaman } \\
(\mathrm{m})\end{array}$ & Nspt & $\begin{array}{c}\mathrm{Y}_{\mathrm{sat}} \\
\left(\mathrm{kN} / \mathrm{m}^{3}\right)\end{array}$ & $\mathrm{e}_{0}$ & Gs & LL $(\%)$ & $\mathrm{IP}(\%)$ & $\mathrm{Cu}(\mathrm{kPa})$ & Wc $(\%)$ & $\mathrm{Cc}$ & $\mathrm{Cs}$ & $\mathrm{Cv}\left(\mathrm{cm}^{2} / \mathrm{s}\right)$ \\
\hline $0-4,5$ & 2,25 & 16,201 & 1,527 & 2,567 & 62,37 & 31,73 & 33,89 & 59,49 & 0,547 & 0,121 & 0,0009 \\
\hline $4,5-7,5$ & 9,07 & 16,632 & 1,435 & 2,615 & 63,47 & 33,94 & 46,24 & 54,88 & 0,519 & 0,118 & 0,0008 \\
\hline $7,5-10,5$ & 8,38 & 16,894 & 1,418 & 2,667 & 66,85 & 38,06 & 37,25 & 53,17 & 0,532 & 0,124 & 0,0007 \\
\hline $10,5-15,5$ & 9,23 & 17,275 & 1,263 & 2,645 & 57,03 & 26,73 & 66,87 & 47,72 & 0,419 & 0,096 & 0,0015 \\
\hline
\end{tabular}

Tabel 2.

Hasil Rekap Data Tanah Dasar BH-2

\begin{tabular}{|c|c|c|c|c|c|c|c|c|c|c|c|}
\hline $\begin{array}{c}\text { Kedalaman } \\
(\mathrm{m})\end{array}$ & Nspt & $\begin{array}{c}\Upsilon_{\mathrm{s} a t} \\
\left(\mathrm{kN} \mathrm{m}^{3}\right)\end{array}$ & $\mathrm{e}_{\mathrm{o}}$ & $\mathrm{Gs}$ & $\mathrm{LL}(\%)$ & $\mathrm{IP}(\%)$ & $\mathrm{Cu}(\mathrm{kPa})$ & $\mathrm{Wc}(\%)$ & $\mathrm{Cc}$ & $\mathrm{Cs}$ & $\mathrm{Cv}\left(\mathrm{cm}^{2} / \mathrm{s}\right)$ \\
\hline $0-4,5$ & 2 & 16.291 & 1.629 & 2.654 & 63,47 & 33,32 & 23,46 & 61,38 & 0,596 & 0,13 & 0,0009 \\
\hline $4,5-7,5$ & 7 & 16.331 & 1.524 & 2.598 & 65,16 & 35,81 & 34,48 & 58,66 & 0,563 & 0,127 & 0,0008 \\
\hline $7,5-10,5$ & 10 & 16.619 & 1.437 & 2.613 & 48,75 & 16,29 & 55,37 & 54,99 & 0,431 & 0,089 & 0,002 \\
\hline
\end{tabular}




\section{Spesifikasi PCI Girder}

$P C I$ Girder yang direncanakan ada 2 tipe yaitu untuk bentang tengah jembatan sepanjang $26 \mathrm{~m}$ adalah $P C I \mathrm{H}-160$ $\mathrm{cm}$ dan bentang sepanjang $17 \mathrm{~m}$ adalah $P C I H-125 \mathrm{~cm}$.

\section{B. Perencanaan Pilar 1 Jembatan (Pilar Tengah)}

\section{Perencanaan Kombinasi Tiang Pancang}

Kombinasi pembebanan dalam perencanaan pilar 1 menggunakan RSNI T - 02 - 2005 [1]. Berikut adalah data perencanaan untuk perhitungan struktur pilar 1 jembatan :

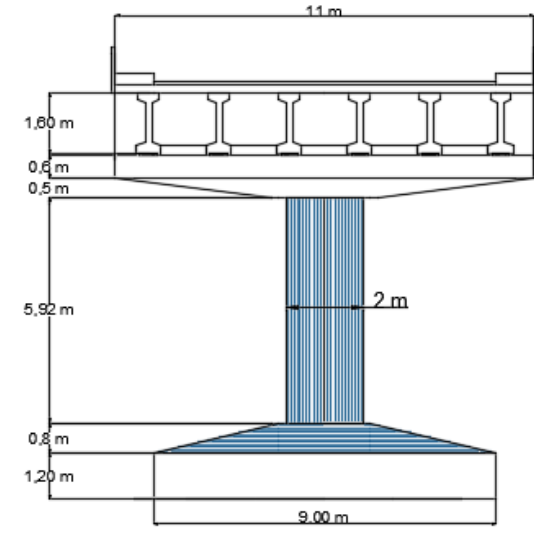

Gambar 4. Perencanaan Pilar 1 Jembatan

Hasil perhitungan kombinasi tiang pancang untuk setiap diameter tiang pancang yang direncakanan, yaitu D40, D50, dan D60 dapat dilihat pada Tabel 3. Tabel 3.

Hasil Perhitungan Kombinasi Tiang Pancang D40, D50, dan D60

\begin{tabular}{|c|c|c|c|c|c|c|c|}
\hline $\begin{array}{c}\text { Diameter } \\
\text { Tiang } \\
\text { Pancang }(\mathrm{m})\end{array}$ & $\mathrm{m}$ & $\mathrm{n}$ & Total & $\begin{array}{c}\mathrm{S}_{\mathrm{m}} \\
(\mathrm{m})\end{array}$ & $\begin{array}{c}\mathrm{S}_{\mathrm{n}} \\
(\mathrm{m})\end{array}$ & $\begin{array}{c}\text { Jarak } \\
\text { Pancang ke } \\
\text { Tepi m }(\mathrm{m})\end{array}$ & $\begin{array}{c}\text { Jarak } \\
\text { Pancang ke } \\
\text { Tepi n }(\mathrm{m})\end{array}$ \\
\hline 0,4 & 7 & 7 & 49 & 1,2 & 1,2 & 0,9 & 0,9 \\
\hline 0,5 & 6 & 6 & 36 & 1,4 & 1,4 & 1 & 1 \\
\hline 0,6 & 5 & 5 & 25 & 1,8 & 1,8 & 0,9 & 0,9 \\
\hline
\end{tabular}

Setelah diketahui jumlah dan kedalaman tiang pancang yang digunakan, maka biaya material dapat dihitung. Berikut adalah hasil perhitungan biaya pada masing-masing diameter tiang pancang yang direncanakan:

$$
\text { Tabel } 4 .
$$

Harga Tiang Pancang yang Direncanakan

\begin{tabular}{|c|c|c|c|c|c|c|}
\hline \multirow{2}{*}{$\begin{array}{c}\mathrm{D} \\
(\mathrm{m})\end{array}$} & \multirow{2}{*}{$\begin{array}{c}\text { Kedalaman } \\
(\mathrm{m})\end{array}$} & \multirow{2}{*}{ Jumlah } & \multicolumn{3}{|c|}{$\begin{array}{c}\text { Kebutuhan Tiang } \\
\text { Pancang }\end{array}$} & \multirow{2}{*}{ Total Biaya } \\
\cline { 4 - 6 } & & $9 \mathrm{~m}$ & $14 \mathrm{~m}$ & $15 \mathrm{~m}$ & \\
\hline 0,4 & 30,5 & 49 & 196 & & & Rp744.800.000 \\
\hline 0,5 & 27,5 & 36 & & 72 & & Rp396.000.000 \\
\hline 0,6 & 27,5 & 25 & & & 50 & Rp335.000.000 \\
\hline
\end{tabular}

Jadi, diameter tiang pancang pada pilar 1 yang digunakan adalah diameter $60 \mathrm{~cm}$.

\section{Perhitungan Penulangan}

Hasil perhitungan penulangan pada pilar 1 sebagai berikut :

Untuk bagian pilecap :

- Tulangan lentur = D25-125

- Tulangan bagi = D16-250

Untuk bagian pier column :

- Tulangan utama =64D25 (dari PCA Column)

Untuk bagian headstock :

- Tulangan lentur = 82D25-130

- Tulangan tekan =71D19-150

- Tulangan geser $=6 \mathrm{D} 13-300$

\section{Perencanaan Pilar 2 Jembatan}

1. Perencanaan Kombinasi Tiang Pancang

Kombinasi pembebanan dalam perencanaan pilar 2 menggunakan RSNI T - 02 - 2005 [1]. Berikut adalah data perencanaan untuk perhitungan struktur pilar 2 jembatan :

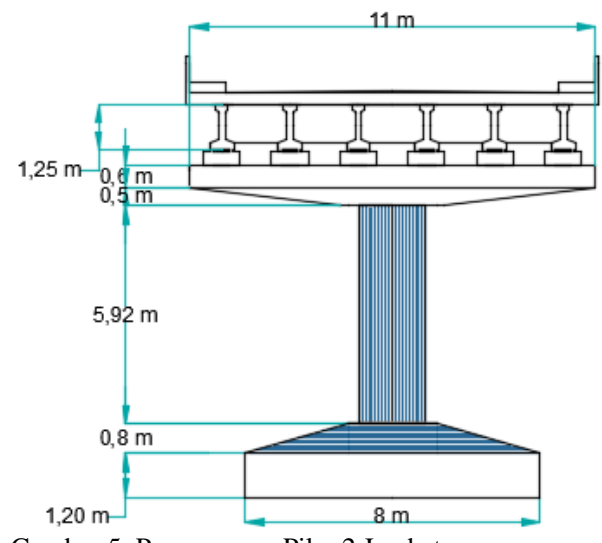

Gambar 5. Perencanaan Pilar 2 Jembatan

Hasil perhitungan kombinasi tiang pancang untuk setiap diameter tiang pancang yang direncakanan, yaitu D40, D50, dan D60 dapat dilihat pada Tabel 5.

$$
\text { Tabel } 5 .
$$

Hasil Perhitungan Kombinasi Tiang Pancang D50 dan D60

\begin{tabular}{|c|c|c|c|c|c|c|c|}
\hline $\begin{array}{c}\text { Diameter } \\
\text { Tiang } \\
\text { Pancang } \\
(\mathrm{m})\end{array}$ & $\mathrm{m}$ & $\mathrm{n}$ & Total & $\begin{array}{c}\mathrm{S}_{\mathrm{m}} \\
(\mathrm{m})\end{array}$ & $\begin{array}{c}\mathrm{S}_{\mathrm{n}} \\
(\mathrm{m})\end{array}$ & $\begin{array}{c}\text { Jarak } \\
\text { Pancang } \\
\text { ke Tepi m } \\
(\mathrm{m})\end{array}$ & $\begin{array}{c}\text { Jarak } \\
\text { Pancang } \\
\text { ke Tepi } \mathrm{n} \\
(\mathrm{m})\end{array}$ \\
\hline 0,5 & 5 & 5 & 25 & 1,5 & 1,5 & 1 & 1 \\
\hline 0,6 & 4 & 4 & 16 & 1,8 & 1,8 & 1,3 & 1,3 \\
\hline
\end{tabular}

Setelah diketahui jumlah dan kedalaman tiang pancang yang digunakan, maka biaya material dapat dihitung. Berikut adalah hasil perhitungan biaya pada masing-masing diameter tiang pancang yang direncanakan: Tabel 6.

Harga Tiang Pancang yang Direncanakan

\begin{tabular}{|c|c|c|c|c|c|}
\hline \multirow{2}{*}{$\begin{array}{c}\mathrm{D} \\
(\mathrm{m})\end{array}$} & $\begin{array}{c}\text { Kedalaman } \\
(\mathrm{m})\end{array}$ & Jumlah & \multicolumn{2}{|c|}{$\begin{array}{c}\text { Kebutuhan Tiang } \\
\text { Pancang }\end{array}$} & \multirow{2}{*}{ Total Biaya } \\
\cline { 4 - 5 } & & & $12 \mathrm{~m}$ & $15 \mathrm{~m}$ & \\
\hline 0,5 & 30,5 & 25 & 75 & & Rp412.500.000 \\
\hline 0,6 & 27,5 & 16 & & 32 & Rp214.400.000 \\
\hline
\end{tabular}

Jadi, diameter tiang pancang pada pilar 2 yang digunakan adalah diameter $60 \mathrm{~cm}$.

\section{Perhitungan Penulangan}

Hasil perhitungan penulangan pada pilar 2 sebagai berikut :

Untuk bagian pilecap :

- Tulangan lentur = D25-125

- Tulangan bagi $=\mathrm{D} 16-250$

Untuk bagian pier column :

- Tulangan utama $=68 \mathrm{D} 22($ dari PCA Column $)$

Untuk bagian headstock :

- Tulangan lentur $=75 \mathrm{D} 25-140$

- Tulangan tekan $=65 \mathrm{D} 19-160$

- Tulangan geser $\quad=6 \mathrm{D} 13-300$

\section{Perencanaan Abutment Jembatan}

\section{Perencanaan Kombinasi Tiang Pancang}

Kombinasi pembebanan dalam perencanaan abutment menggunakan RSNI T - 02 - 2005 [1]. Berikut adalah data perencanaan untuk perhitungan struktur abutment jembatan : 


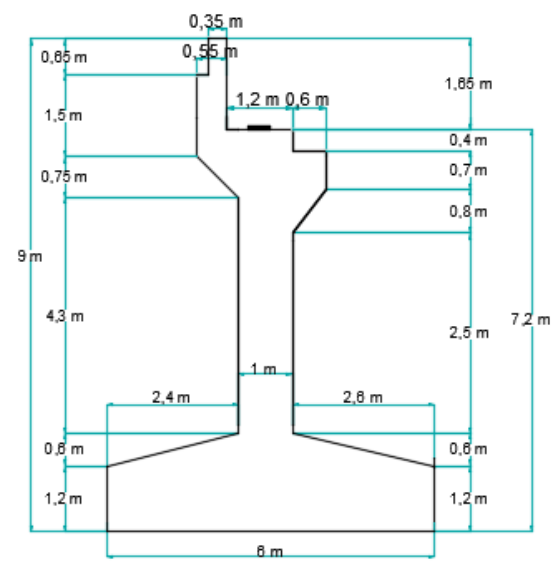

Gambar 6. Perencanaan abutment Jembatan

Hasil perhitungan kombinasi tiang pancang untuk setiap diameter tiang pancang yang direncanakan, yaitu D40, D50, dan D60 dapat dilihat pada Tabel 7.

Tabel 7.

Hasil Perhitungan Kombinasi Tiang Pancang D40, D50 dan D60

\begin{tabular}{|c|c|c|c|c|c|c|c|}
\hline $\begin{array}{c}\text { Diameter } \\
\text { Tiang } \\
\text { Pancang } \\
(\mathrm{m})\end{array}$ & $\mathrm{m}$ & $\mathrm{n}$ & Total & $\begin{array}{c}\mathrm{S}_{\mathrm{m}} \\
(\mathrm{m})\end{array}$ & $\begin{array}{c}\mathrm{S}_{\mathrm{n}} \\
(\mathrm{m})\end{array}$ & $\begin{array}{c}\text { Jarak } \\
\text { Pancang } \\
\text { ke Tepi m } \\
(\mathrm{m})\end{array}$ & $\begin{array}{c}\text { Jarak } \\
\text { Pancang } \\
\text { ke Tepi } \mathrm{n} \\
(\mathrm{m})\end{array}$ \\
\hline 0,4 & 5 & 8 & 40 & 1,1 & 1,2 & 0,8 & 0,8 \\
\hline 0,5 & 4 & 7 & 28 & 1,3 & 1,3 & 1 & 1 \\
\hline 0,6 & 4 & 6 & 24 & 1,3 & 1,6 & 1 & 1 \\
\hline
\end{tabular}

Setelah diketahui jumlah dan kedalaman tiang pancang yang digunakan, maka biaya material dapat dihitung. Berikut adalah hasil perhitungan biaya pada masing-masing diameter tiang pancang yang direncanakan:

Tabel 8.

Harga Tiang Pancang yang Direncanakan

\begin{tabular}{|c|c|c|c|c|c|c|}
\hline \multirow{2}{*}{$\begin{array}{c}\mathrm{D} \\
(\mathrm{m})\end{array}$} & \multirow{2}{*}{$\begin{array}{c}\text { Kedalaman } \\
(\mathrm{m})\end{array}$} & \multirow{2}{*}{ Jumlah } & \multicolumn{3}{|c|}{$\begin{array}{c}\text { Kebutuhan Tiang } \\
\text { Pancang }\end{array}$} & \multirow{2}{*}{ Total Biaya } \\
\cline { 4 - 6 } & & $9 \mathrm{~m}$ & $12 \mathrm{~m}$ & $15 \mathrm{~m}$ & \\
\hline 0,4 & 30,5 & 40 & 160 & & & Rp608.000.000 \\
\hline 0,5 & 30,5 & 28 & & 84 & & Rp462.000.000 \\
\hline 0,6 & 27,5 & 24 & & & 48 & Rp321.600.000 \\
\hline
\end{tabular}

Jadi, diameter tiang pancang pada abutment yang digunakan adalah diameter $60 \mathrm{~cm}$.

\section{Perhitungan Penulangan}

Hasil perhitungan penulangan pada abutment sebagai berikut :

Untuk bagian pilecap :

- Tulangan lentur = D25-125

- Tulangan bagi = D16-250

Untuk bagian breast wall :

- Tulangan lentur = D25-150

- Tulangan bagi = D16-300

Untuk bagian backwall :

- Tulangan lentur = D16-115

- Tulangan bagi = D13-75

\section{E. Perhitungan Besar Pemampatan (Sc) dan Tinggi} Timbunan Awal (H inisial)

Formula dalam menghitung besar Sc menggunakan rumus Terzaghi (1942) [2]. Perhitungan besar pemampatan dilakukan untuk mencari tinggi timbunan awal yang dibutuhkan untuk mencapai tinggi rencana setiap ketinggian oprit yaitu $8 \mathrm{~m}, 7 \mathrm{~m}, 6 \mathrm{~m}, 5 \mathrm{~m}, 4 \mathrm{~m}, 3 \mathrm{~m}$. Perencanaan $\mathrm{H}_{\text {inisial }}$ dalam Penelitian ini memperhitungkan beban timbunan, beban traffic, dan beban perkerasan.

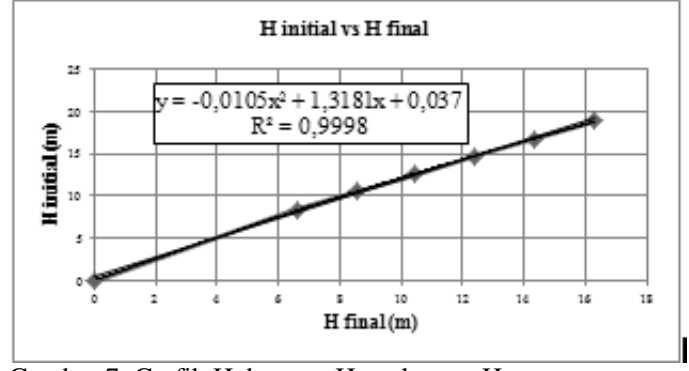

Gambar 7. Grafik Hubungan $\mathrm{H}_{\text {final }}$ dengan $\mathrm{H}_{\text {inisial }}$

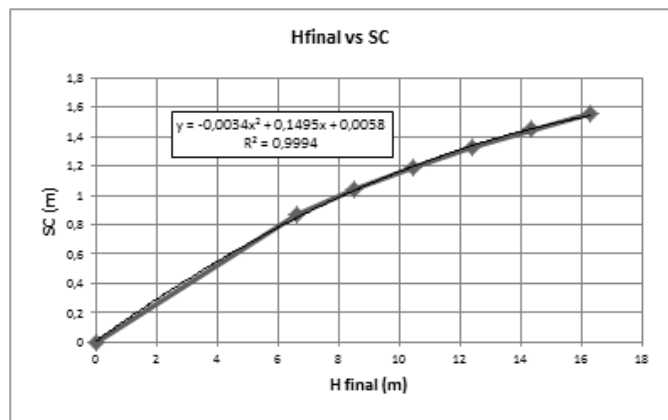

Gambar 8. Grafik Hubungan $\mathrm{H}_{\text {final }}$ dengan Settlement

Dari grafik-grafik di atas dapat ditentukan $\mathrm{H}_{\text {inisial }}$ dan settlement yang terjadi pada setiap ketinggian oprit yang direncanakan, yaitu (Tabel 9) :

Tabel 9.

$\mathrm{H}_{\text {inisial }}(\mathrm{m})$ dan Sc (m)

\begin{tabular}{|c|c|c|}
\hline $\mathrm{H}_{\text {final }}(\mathrm{m})$ & $\mathrm{H}_{\text {inisial }}(\mathrm{m})$ & $\mathrm{Sc}(\mathrm{m})$ \\
\hline 8 & 9,9 & 0,984 \\
\hline 7 & 8,7 & 0,886 \\
\hline 6 & 7,6 & 0,780 \\
\hline 5 & 6,4 & 0,668 \\
\hline 4 & 5,1 & 0,549 \\
\hline 3 & 3,9 & 0,424 \\
\hline
\end{tabular}

\section{F. Perencanaan Perbaikan Tanah dengan PVD}

Waktu konsolidasi alami yang terjadi cukup lama yaitu hingga 67 tahun, sehingga diperlukan Prefabricated Vertical Drain (PVD) untuk mempercepat waktu konsolidasi.

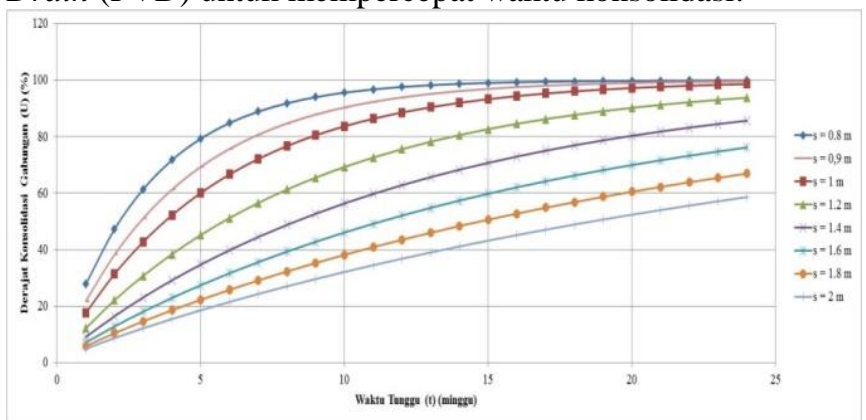

Gambar 9. Grafik Hubungan Waktu dengan Derajat Konsolidasi (U) dengan menggunakan PVD Pola Segiempat

PVD yang digunakan dalam perencanaan adalah menggunakan pola segiempat dengan jarak antar PVD adalah 1,2 m. karena kemudahan pelaksanaan pemasangan PVD di lapangan dan jika dibandingkan dengan jarak $\mathrm{s}=1$ meter, beda waktu yang terjadi sekitar 7 minggu. Karena waktu yang disediakan cukup untuk $\mathrm{s}=1,2$ meter, maka diputuskan untuk penggunaan spasi PVD adalah 1,2 meter. Dengan pertimbangan yang lain adalah mahalnya harga material PVD. 


\section{G. Perencanaan Geotextile Walls sebagai Perkuatan Oprit Timbunan (Alternatif 1)}

Geotextile yang digunakan pada perencanaan adalah UW-250 dengan $T_{\text {ult }} 52 \mathrm{kN} / \mathrm{m}$. Berikut adalah hasil perhitungan kebutuhan geotextile pada $\mathrm{H}$ oprit $8 \mathrm{~m}$ (Tabel $10)$.

Tabel 10.

Perhitungan Kebutuhan Geotextile untuk H oprit $8 \mathrm{~m}$

\begin{tabular}{|c|c|c|c|c|c|c|c|c|c|c|}
\hline No & $\mathrm{z}(\mathrm{m})$ & \begin{tabular}{|l}
$\sigma \mathrm{H}$ total \\
$(\mathrm{kN} / \mathrm{m} 2)$
\end{tabular} & $\begin{array}{l}\text { Jumlah } \\
\text { Lembar }\end{array}$ & $\mathrm{Sv}(\mathrm{m})$ & $\begin{array}{c}\text { Sv pakai } \\
\text { (m) }\end{array}$ & $\mathrm{Le}(\mathrm{m})$ & $\begin{array}{c}\begin{array}{c}\text { Le pakai } \\
\text { (m) }\end{array} \\
\end{array}$ & $\operatorname{Lr}(\mathrm{m})$ & \begin{tabular}{|c}
$\begin{array}{c}\text { Lo pakai } \\
(\mathrm{m})\end{array}$ \\
\end{tabular} & Ltotal (m) \\
\hline 1 & 0,8 & 10,53 & 1,00 & 1,20 & 0,8 & 0,81 & 1 & 4,16 & 1 & 7,3 \\
\hline 2 & 1,6 & 15,33 & 1,00 & 0,82 & 0,8 & 0,59 & 1 & 3,70 & 1 & 7,3 \\
\hline 3 & 2 & 17,73 & 1,00 & 0,71 & 0,4 & 0,27 & 1 & 3,46 & 1 & 6,9 \\
\hline 4 & 2,4 & 20,13 & 1,00 & 0,63 & 0,4 & 0,26 & 1 & 3,23 & 1 & 6,9 \\
\hline 5 & 2,8 & 22,53 & 1,00 & 0,56 & 0,4 & 0,25 & 1 & 3,00 & 1 & 6,9 \\
\hline 6 & 3,2 & 24,93 & 1,00 & 0,51 & 0,4 & 0,24 & 1 & 2,77 & 1 & 6,9 \\
\hline 7 & 3,6 & 27,33 & 1,00 & 0,46 & 0,4 & 0,23 & 1 & 2,54 & 1 & 6,9 \\
\hline 8 & 4 & 29,73 & 1,00 & 0,42 & 0,4 & 0,23 & 1 & 2,31 & 1 & 6,9 \\
\hline 9 & 4,4 & 32,13 & 1,00 & 0,39 & 0,4 & 0,22 & 1 & 2,08 & 1 & 6,9 \\
\hline 10 & 4,6 & 33,33 & 1,00 & 0,38 & 0,2 & 0,11 & 1 & 1,96 & 1 & 6,7 \\
\hline 11 & 4,8 & 34,53 & 1,00 & 0,37 & 0,2 & 0,11 & 1 & 1,85 & 1 & 6,7 \\
\hline 12 & 5 & 35,73 & 1,00 & 0,35 & 0,2 & 0,11 & 1 & 1,73 & 1 & 6,7 \\
\hline 13 & 5,2 & 36,93 & 1,00 & 0,34 & 0,2 & 0,11 & 1 & 1,62 & 1 & 6,7 \\
\hline 14 & 5,4 & 38,13 & 1,00 & 0,33 & 0,2 & 0,11 & 1 & 1,50 & 1 & 6,7 \\
\hline 15 & 5,6 & 39,33 & 1,00 & 0,32 & 0,2 & 0,11 & 1 & 1,39 & 1 & 6,7 \\
\hline 16 & 5,8 & 40,53 & 1,00 & 0,31 & 0,2 & 0,11 & 1 & 1,27 & 1 & 6,7 \\
\hline 17 & 6 & 41,73 & 1,00 & 0,30 & 0,2 & 0,11 & 1 & 1,15 & 1 & 6,7 \\
\hline 18 & 6,2 & 42,93 & 1,00 & 0,29 & 0,2 & 0,11 & 1 & 1,04 & 1 & 6,7 \\
\hline 19 & 6,4 & 44,13 & 1,00 & 0,29 & 0,2 & 0,11 & 1 & 0,92 & 1 & 6,7 \\
\hline 20 & 6,6 & 45,33 & 1,00 & 0,28 & 0,2 & 0,11 & 1 & 0,81 & 1 & 6,7 \\
\hline 21 & 6,8 & 46,53 & 1,00 & 0,27 & 0,2 & 0,11 & 1 & 0,69 & 1 & 6,7 \\
\hline 22 & 7 & 47,73 & 1,00 & 0,26 & 0,2 & 0,10 & 1 & 0,58 & 1 & 6,7 \\
\hline 23 & 7,2 & 48,93 & 1,00 & 0,26 & 0,2 & 0,10 & 1 & 0,46 & 1 & 6,7 \\
\hline 24 & 7,4 & 50,13 & 1,00 & 0,25 & 0,2 & 0,10 & 1 & 0,35 & 1 & 6,7 \\
\hline 25 & 7,6 & 51,33 & 1,00 & 0,25 & 0,2 & 0,10 & 1 & 0,23 & 1 & 6,7 \\
\hline 26 & 7,8 & 52,53 & 1,00 & 0,24 & 0,2 & 0,10 & 1 & 0,12 & 1 & 6,7 \\
\hline 27 & 8 & 53,73 & 1,00 & 0,23 & 0,2 & 0,10 & 1 & 0,00 & 1 & 6,7 \\
\hline
\end{tabular}

Analisis overall stability menggunakan metode Bishop [3]. Berikut adalah sketsa pemasangan geotextile walls arah melintang dan memanjang jembatan untuk ketinggian oprit timbunan $8 \mathrm{~m}$ :

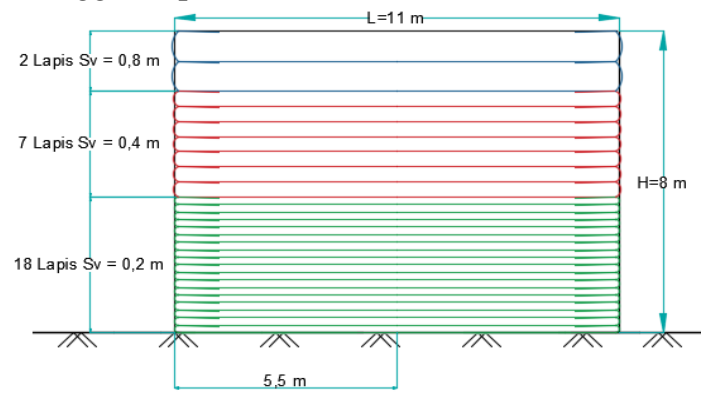

Gambar 10. Sketsa Pemasangan Geotextile Wall untuk Ketinggian Oprit 8 m

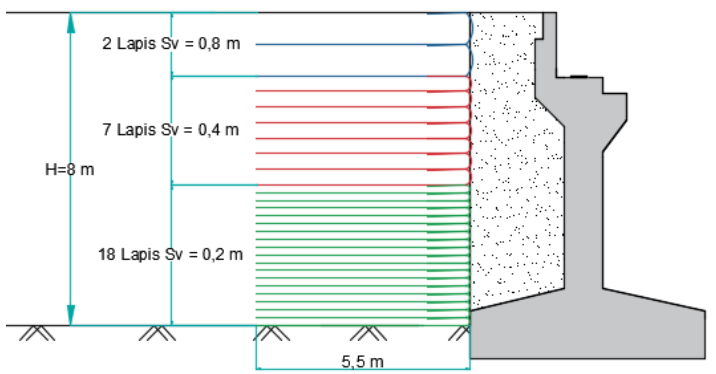

Gambar 11. Sketsa Pemasangan Geotextile Wall Arah Memanjang

\section{H. Perencanaan Freyssisol sebagai Perkuatan Oprit Timbunan (Alternatif 2)}

Paraweb straps yang digunakan pada Penelitian ini memiliki Tu sebesar $30 \mathrm{kN}, 50 \mathrm{kN}$, dan $100 \mathrm{kN}$ [4]. Berikut adalah hasil perhitungan kebutuhan paraweb straps pada $\mathrm{H}$ oprit $8 \mathrm{~m}$ (Tabel 3.11).
Tabel 11

Perhitungan Kebutuhan Paraweb Strps, H oprit $8 \mathrm{~m}$

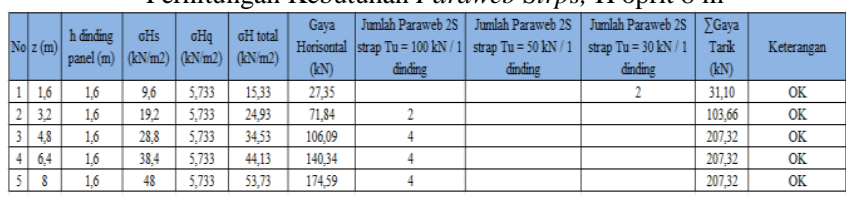

Berikut adalah sketsa pemasangan freyssisol untuk ketinggian oprit timbunan $8 \mathrm{~m}$ dan geotextile wall arah memanjang jembatan :

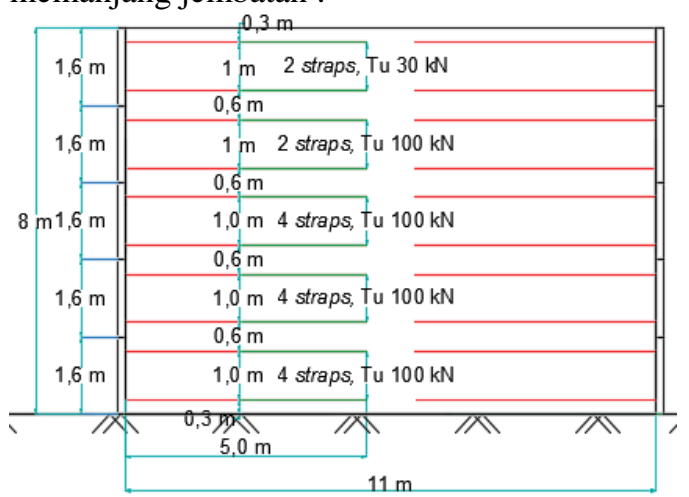

Gambar 12. Sketsa Pemasangan Freyssisol untuk Ketinggian Oprit 8 m

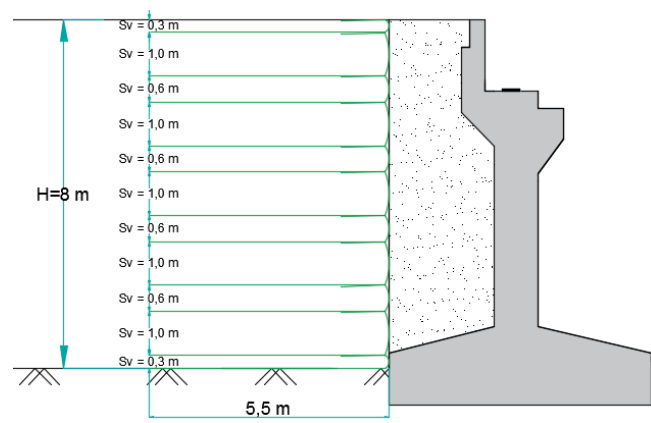

Gambar 13. Sketsa Pemasangan Geotextile Wall Arah Memanjang

\section{Perhitungan Biaya Material}

Total kebutuhan dan biaya material pada alternatif 1 dapat dilihat pada Tabel 12 .

Tabel 12.

Total Kebutuhan dan Biaya Material pada Alternatif 1

\begin{tabular}{|c|c|c|c|c|c|}
\hline No & Pekerjaan & Volume & Satuan & Harga Satuan & Total Harga \\
\hline 1 & Timbunan & 15840 & $\mathrm{~m}^{3}$ & Rp230.000 & Rp3.643.200.000 \\
\hline 2 & PVD & 44640 & $\mathrm{~m}$ & $\mathrm{Rp} 3.500$ & $\mathrm{Rp} 156.240 .000$ \\
\hline 3 & PHD & 3520 & $\mathrm{~m}$ & $\mathrm{Rp} 117.000$ & Rp411.840.000 \\
\hline 4 & Geotextile (melintang) & 43720 & $\mathrm{~m}^{2}$ & Rp17.000 & Rp743.240.000 \\
\hline 5 & Geotextile (memanjang) & 4037 & $\mathrm{~m}^{2}$ & Rp17.000 & Rp68.629.000 \\
\hline 6 & Dinding Penutup & 1440 & $\mathrm{~m}^{2}$ & Rp198.000 & Rp285.120.000 \\
\hline \multicolumn{7}{|c}{$\sum$} & Rp5.308.269.000 \\
\hline
\end{tabular}

Perhitungan harga paraweb straps yang dibutuhkan dalam perencaaan pada setiap ketiaan oprit timbunan dapat dilihat pada Tabel 13 dan total kebutuhan dan biaya material pada alternatif 2 dapat dilihat pada Tabel 14. 
Tabel 13.

Perhitungan Harga Paraweb Straps pada Setiap Ketinggian Oprit Timbunan

\begin{tabular}{|c|c|c|c|c|c|}
\hline $\mathbf{T u}(\mathbf{k N})$ & H (m) & Berat (kg) & Total (kg) & Harga Satuan & Total Harga \\
\hline \multirow{6}{*}{30} & 8 & 30,53 & \multirow{6}{*}{183,20} & \multirow{6}{*}{ Rp68.422 } & \multirow{6}{*}{ Rp12.534.715 } \\
\hline & 7 & 30,53 & & & \\
\hline & 6 & 30,53 & & & \\
\hline & 5 & 30,53 & & & \\
\hline & 4 & 30,53 & & & \\
\hline & 3 & 30,53 & & & \\
\hline \multirow{6}{*}{50} & 8 & - & \multirow{6}{*}{967,87308} & \multirow{6}{*}{ Rp68.026 } & \multirow{6}{*}{ Rp65.840.534 } \\
\hline & 7 & 184,19 & & & \\
\hline & 6 & 184,19 & & & \\
\hline & 5 & 184,19 & & & \\
\hline & 4 & 231,12 & & & \\
\hline & 3 & 184,19 & & & \\
\hline \multirow{6}{*}{100} & 8 & 960,76 & \multirow{6}{*}{2587,10} & \multirow{6}{*}{ Rp68.817 } & \multirow{6}{*}{ Rp178.036.491 } \\
\hline & 7 & 665,58 & & & \\
\hline & 6 & 590,37 & & & \\
\hline & 5 & 370,39 & & & \\
\hline & 4 & - & & & \\
\hline & 3 & - & & & \\
\hline & & & & $\sum$ & Rp256.411.740 \\
\hline
\end{tabular}

Tabel 14.

Total Kebutuhan dan Biaya Material pada Alternatif 2

\begin{tabular}{|c|c|c|c|c|c|}
\hline No & Pekerjaan & Volume & Satuan & Harga Satuan & Total Harga \\
\hline 1 & Timbunan & 15840 & $\mathrm{~m}^{3}$ & Rp230.000 & Rp3.643.200.000 \\
\hline 2 & PVD & 44640 & $\mathrm{~m}$ & Rp3.500 & Rp156.240.000 \\
\hline 3 & PHD & 3520 & $\mathrm{~m}$ & Rp117.000 & Rp411.840.000 \\
\hline 4 & $\begin{array}{c}\text { Paraweb 2S Straps } \\
\text { (Freyssisol) }\end{array}$ & - & - & - & Rp512.823.480 \\
\hline 5 & \begin{tabular}{|c|} 
Precast Concrete Wall \\
(Freyssisol)
\end{tabular} & 230,4 & $\mathrm{~m}^{3}$ & Rp820.000 & Rp188.928.000 \\
\hline 6 & Geotextile (memanjang) & 1749 & $\mathrm{~m}^{2}$ & Rp17.000 & Rp29.733.000 \\
\hline
\end{tabular}

\section{J. Metode Pelaksanaan Perbaikan dan Perkuatan Tanah}

1. Metode Pelaksanaan Geotextile Walls (Alternatif 1)

- Pekerjaan Persiapan.

- Penggalian dan pengurugan kembali tanah dasar sedalam $1 \mathrm{~m}$ dengan tanah yang memiliki nilai $\mathrm{c}$ tertentu.

- Pemasangan Prefabricated Vertical Drain (PVD).

- Pemasangan Prefabricated Horizontal Drain (PHD).

- Pekerjaan Sloof.

- Pemasangan panel beton segmental (dinding sebagai facing).

- Pengurugan sirtu (tanah timbunan) .

- Pemasangan geotextile.

- Penggalian finishing.

2. $\quad$ Metode Pelaksanaan Freyssisol (Alternatif 2)

- Pekerjaan Persiapan

- Penggalian dan pengurugan kembali tanah dasar sedalam $1 \mathrm{~m}$ dengan tanah yang memiliki nilai c tertentu.

- Pemasangan Prefabricated Vertical Drain (PVD).

- Pemasangan Prefabricated Horizontal Drain (PHD).

- Pekerjaan Sloof.

- Pemasangan dinding precast

- Pemasangan paraweb straps

Pekerjaan pemasangan paraweb straps dengan dinding precast dapat dilihat pada Gambar 14.

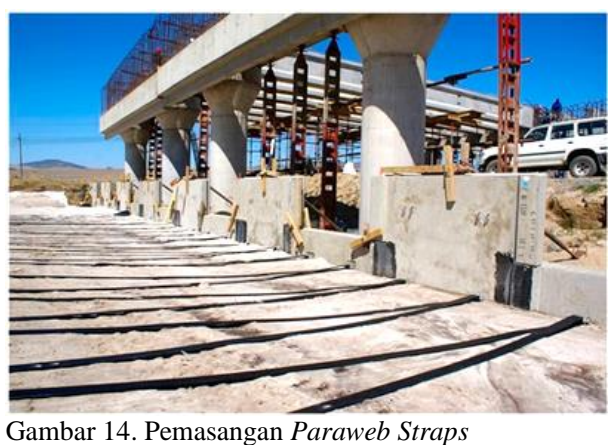

- Pengurugan sirtu (tanah timbunan)

- Pekerjaan finishing

\section{KESIMPULAN}

Dalam perencanaan Penelitian ini didapatkan beberapa kesimpulan sebagai berikut :

1. Berikut adalah hasil perencanaan pondasi pada pilar dan abutment jembatan (Tabel 15).

Tabel 15.

Rekap Hasil Perencanaan Pondasi pada Pilar dan Abutment Jembatan

\begin{tabular}{|c|c|c|c|c|c|}
\hline No & Perencanaan & $\begin{array}{c}\text { Diameter } \\
\text { tiang }(\mathrm{cm})\end{array}$ & $\begin{array}{c}\text { Jumlah } \\
\text { tiang }\end{array}$ & $\begin{array}{c}\text { Kedalaman } \\
(\mathrm{m})\end{array}$ & Biaya Material \\
\hline 1 & Pilar 1 & 60 & 25 & 27,5 & $\mathrm{Rp} 335.000 .000$ \\
\hline 2 & Pilar 2 & 60 & 16 & 27,5 & $\mathrm{Rp} 214.400 .000$ \\
\hline 3 & Abutment & 60 & 24 & 27,5 & $\mathrm{Rp} 321.600 .000$ \\
\hline
\end{tabular}

Berikut adalah hasil perhitungan penulangan pada pilar dan abutment jembatan (Tabel 16 dan Tabel 17).

Tabel 16.

Rekap Hasil Perhitungan Penulangan pada Pilar Jembatan

\begin{tabular}{|c|c|c|c|c|c|c|c|}
\hline \multirow{2}{*}{ No } & \multirow{2}{*}{ Pilar } & \multicolumn{2}{|c|}{ Pilecap } & $\begin{array}{c}\text { Pier } \\
\text { Column }\end{array}$ & \multicolumn{3}{c|}{ Headstock } \\
\cline { 3 - 8 } & $\begin{array}{c}\text { Tul. } \\
\text { Lentur }\end{array}$ & $\begin{array}{c}\text { Tul. } \\
\text { Bagi }\end{array}$ & $\begin{array}{c}\text { Tul. } \\
\text { Utama }\end{array}$ & Tul. Lentur & Tul. Tekan & Tul. Geser \\
\hline 1 & Pilar 1 & D25-125 & D16-250 & 64D25 & 82D25-130 & 71D19-150 & 6D13-300 \\
\hline 2 & Pilar 2 & D25-125 & D16-250 & 68D22 & 75D25-140 & 65D19-160 & 6D13-300 \\
\hline
\end{tabular}

Tabel 17

Rekap Hasil Perhitungan Penulangan pada Abutment Jembatan

\begin{tabular}{|c|c|c|c|c|c|c|c|}
\hline \multirow{2}{*}{ No } & \multirow{2}{*}{ Perencanaan } & \multicolumn{2}{|c|}{ Pilecap } & \multicolumn{2}{c|}{ Breast Wall } & \multicolumn{2}{c|}{ Back Wall } \\
\cline { 3 - 8 } & & Tul. Lentur & Tul. Bagi & Tul. Lentur & Tul. Bagi & Tul. Lentur & Tul. Bagi \\
\hline 1 & Abutment & D25-125 & D16-250 & D25-150 & D16-300 & D16-115 & D13-75 \\
\hline
\end{tabular}

2. Pola pemasangan PVD adalah segiempat dengan jarak antar PVD adalah 1,2 m. Kedalaman PVD yang direncanakan adalah $15,5 \mathrm{~m}$. Pola pemasangan PHD adalah selebar oprit timbunan dan jarak horisontal antar PHD adalah 1,2 m.

3. Pada perencanaan perkuatan timbunan alternatif 1 yaitu dengan geotextile wall didapatkan luas total geotextile yang diperlukan sebagai berikut :
- Geotextile arah melintang
$=43720 \mathrm{~m}^{2}$
- Geotextile arah memanjang
$=4037 \mathrm{~m}^{2}$

4. Pada perencanaan perkuatan timbunan alternatif 2 yaitu dengan freyssisol didapatkan total kebutuhan paraweb straps dan geotextile yang diperlukan sebagai berikut :
- Paraweb straps
$=3738,17 \mathrm{~kg}$
- Geotextile arah memanjang
$=1749 \mathrm{~m}^{2}$

5. Penulis memilih alternatif 1 sebagai perkuatan timbunan. Alasan Penulis memilih alternatif 1 adalah ketersediaan material geotextile lebih mudah didapat di Indonesia daripada alternatif 2 yaitu menggunakan freyssisol. Selain itu, Penulis juga mempertimbangkan kesalahan dalam asumsi harga yang digunakan. Karena dalam Penelitian ini, harga satuan untuk paraweb straps pada alternatif 2 adalah asumsi dengan menggunakan harga di luar Indonesia. 


\section{DAFTAR PUSTAKA}

[1] Badan Standardisasi Nasional (BSN). Standar Pembebanan untuk Jembatan (RSNI T - 02 - 2005).

[2] Mochtar, Noor Endah. 2012. Modul Ajar Metode Perbaikan Tanah. Surabaya: Jurusan Teknik Sipil FTSP-ITS.

[3] Das, Braja M. 1988. Mekanika Tanah: Prinsip-Prinsip Rekayasa Geoteknik jilid 2. Diterjemahkan oleh Noor Endah dan Indrasurya B.M. Surabaya: Erlangga.

[4] Terre Armée, 2007. Specificatii Tehnice-Pamant Armant Cu Ziduri Tip Freyssisol. <URL: http://www.proidea.ro/terre-armee-romaniasrl229102/freyssisol-pamant-armatzidarie-352525.shtml>. 